\title{
Comparative Efficacy of Three Brands of Gum Acacia on Adenine- Induced Chronic Renal Failure in Rats
}

\author{
B. H. ALI ${ }^{1}$, S. BEEGAM ${ }^{1}$, I. AL-LAWATI ${ }^{1}$, M. I. WALY ${ }^{2}$, M. AL ZA'ABI ${ }^{1}$, A. NEMMAR ${ }^{3}$ \\ ${ }^{1}$ Department of Pharmacology and Clinical Pharmacy, College of Medicine and Health Sciences, \\ and ${ }^{2}$ Department of Food Science and Nutrition, College of Agriculture, Sultan Qaboos University, \\ Al Khod, Oman, ${ }^{3}$ Department of Physiology, Faculty of Medicine, UAE University, Al Ain, UAE
}

Received May 2, 2012

Accepted August 10, 2012

On-line November 22, 2012

\section{Summary}

Gum acacia (GA) is used in pharmaceutical, cosmetic and food industries as an emulsifier and stabilizer, and in some countries in the traditional treatment of patients with chronic kidney disease (CKD). We have previously found that GA ameliorates adenine -induced chronic renal failure (CRF) in rats. Different brands of GA are commercially available, but their comparative efficacy against adenine-induced CKD is unknown. Here, we explored the effects of three different brands of GA (Sudanese $\mathrm{GA}$, Supergum ${ }^{\mathrm{TM}}$ and $\mathrm{GA}$ from $\mathrm{BDH}$ ) on some physiological, biochemical, and histological effects of adenine-induced CRF in rats. Adenine $(0.75 \%, w / w$ in feed, four weeks) reduced body weight, and increased urine output. It also induced significant increases in blood pressure, and in creatinine, urea, several inflammatory cytokines in plasma, and indices of oxidative stress, and caused histological damage in kidneys. Treatment of rats concomitantly with any of the three GA brands, significantly, and to a broadly similar extent, mitigated all the signs of CRF. The results suggested equivalent efficacy of these brands in antagonizing the CRF in this animal model. However, to enable standardization of different brands between laboratories, the use of the chemically well-characterized GA preparation (such as Supergum ${ }^{\mathrm{TM}}$ ) is recommended.

\section{Key words}

Adenine • Animal model • Chronic kidney disease • Gum acacia • Rats

\section{Corresponding author}

Badreldin H. Ali, Department of Pharmacology, College of Medicine and Health Sciences, Sultan Qaboos University, P. O. Box 35 Al Khod, Postal code 123, Oman. E-mail: alibadreldin@hotmail.com and akthmali@squ.edu.om

\section{Introduction}

Gum acacia (GA) is a dietary fibrous heteropolysaccharide obtained from either Acacia senegal or $A$. seyal trees, which are cultivated in the Sudan as a cash crop in agroforestry systems (Lelon et al. 2010). The gum has a high molecular weight (approx. 350-850 kDa) and has galactose $(44 \%)$, rhamnose $(13 \%)$, glucuronic acid $(16 \%)$ and arabinose $(27 \%)$ residues, but also minerals like potassium, magnesium and calcium (Williams and Phillips 2000, Al-Assaf et al. 2005, Ali et al. 2008). GA is widely employed in the pharmaceutical, cosmetic and food industries as an emulsifier and stabilizer. It is also used in the traditional treatment of patients with chronic kidney disease (CKD) in some Middle Eastern countries, such as the Sudan (Ali et al. 2009). Addition of GA to the diet has been shown to increase fecal nitrogen excretion and decrease serum urea nitrogen concentration in patients with CKD, and this was shown to be dependent on increased bacterial growth and activity in the gut (Bliss et al. 1996). Colonic bacteria produce ureases that hydrolyze urea to ammonia and carbon dioxide. The resultant ammonia can then be incorporated into bacterial proteins, which are subsequently excreted in the bacterial mass fraction of the feces. The net result is increased $\mathrm{N}$ excretion in the feces. Using a chemically-induced model of chronic renal failure (CRF) in rats, we have shown that GA is effective in significantly ameliorating some of the physiological, biochemical and histopathological actions of CRF (Ali et al. 2010), and some of its consequences on behavior (Ali et al. 2011a) and blood pressure (Ali et al. 2011b). The 
basis of the salutary action of GA on CRF was suggested to be via an anti-inflammatory and antioxidant action (Ali et al. 2010).

GA is a natural product and its chemical composition (and probably its pharmacological properties) may well vary with the source, and may not always be consistent or stable, depending on several climatic factors, edaphic conditions, season, age of the tree from which the gum is collected, and other variables. We used, in each of our previous publications, a single source of GA. We thought it might be useful to conduct a separate experiment in which we compare the effect of GA from three different sources in rats with CRF. The objective is to find out which variety would afford better amelioration of the different indices of CKD. In this comparative study we used finely-powdered GA from Sudan (Nature Gums, Khartoum, Sudan), GA sold by British Drug Houses, BDH (UK), and a well

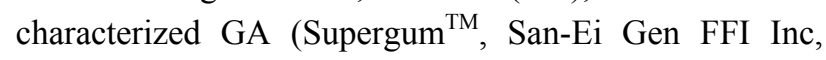
Japan), whose molecular parameters have been determined (Cui et al. 2007).

\section{Methods}

Animals

Male Wistar rats, initially weighing 300-400 g, were obtained from Sultan Qaboos University Animal House. The rats were housed in polypropylene cages and maintained under standard conditions $\left[22 \pm 2{ }^{\circ} \mathrm{C} ; 12 \mathrm{~L}\right.$ : $12 \mathrm{D}$ cycle (lights on at 07:00 hr); and about $60 \%$ humidity].The animals had free access to water and a feed composed of standard powder diet containing $0.85 \%$ phosphorus, $1.12 \%$ calcium, $0.35 \%$ magnesium, $25.3 \%$ crude protein and $2.5 \mathrm{IU} / \mathrm{g}$ vitamin D3 (Oman Flour Mills, Muscat, Oman). The study was approved by the University Animal Ethical Committee and was conducted in conformity with international laws and policies (EEC Council directives 86 / 609, OJL 358, 1 December, 12, 1987; NIH Guide for the Care and Use of Laboratory Animals, NIH Publications No. 85-23, 1985).

\section{Experimental design}

After an acclimatization period of seven days, rats were randomly divided into eight groups of six rats each and were given the following treatments for four consecutive weeks:

Group 1: Control received normal food and water.

Group 2: Received food thoroughly mixed with adenine $(0.75 \% \mathrm{w} / \mathrm{w})$.
Group 3: Received normal food plus Sudanese GA in the drinking water $(15 \% \mathrm{w} / \mathrm{v})$.

Group 4: Received food thoroughly mixed with adenine $(0.75 \% \mathrm{w} / \mathrm{w})$ plus Sudanese GA in drinking water $(15 \%, \mathrm{w} / \mathrm{v})$.

Group 5: Received normal food plus Supergum ${ }^{\mathrm{TM}}$ in the drinking water $(15 \% \mathrm{w} / \mathrm{v})$.

Group 6: Received food thoroughly mixed with adenine $(0.75 \% \mathrm{w} / \mathrm{w})$ plus Supergum ${ }^{\mathrm{TM}}$ in the drinking water $(15 \% \mathrm{w} / \mathrm{v})$.

Group 7: Received normal food plus GA (BDH) in the drinking water $(15 \% \mathrm{w} / \mathrm{v})$.

Group 8: Received food thoroughly mixed with adenine $(0.75 \% \mathrm{w} / \mathrm{w})$ plus GA $(\mathrm{BDH})$ in the drinking water $(15 \% \mathrm{w} / \mathrm{v})$.

All the experimental procedures were conducted by technicians unaware of the type of GA used. Just before the treatment, at weekly intervals thereafter, and just before killing, the body weights of all rats were recorded. Before starting the treatments, and at their end, systolic and diastolic blood pressure and heart rates were measured. At the end of the treatment, the animals were placed in metabolic cages one day before being killed, and the amount of water consumed was recorded, and the urine voided for $24 \mathrm{hrs}$ was collected. Thereafter, rats were anesthetized by intraperitoneal injection of ketamine $(75 \mathrm{mg} / \mathrm{kg})$ and xylazine $(5 \mathrm{mg} / \mathrm{kg})$, and blood $(5 \mathrm{ml})$ collected from the anterior vena cava was placed into heparinized tubes. The blood and urine were centrifuged at $900 \mathrm{~g}$ at $4{ }^{\circ} \mathrm{C}$ for $15 \mathrm{~min}$. The plasma obtained, together with the urine specimens, were stored frozen at $-80{ }^{\circ} \mathrm{C}$ pending analysis. The two kidneys were excised, cleared of fat and weighed. A small piece of the left kidney was placed in $10 \%$ buffered formalin for subsequent histological processing. The rest of the kidneys were kept frozen at $-80{ }^{\circ} \mathrm{C}$ to await biochemical analysis.

\section{Tissue homogenization}

A portion of rat kidney tissues $(0.5 \mathrm{~g})$ was homogenized in $10 \mathrm{ml}$ of $100 \mathrm{mM}$ potassium phosphate buffer ( $\mathrm{pH}$ 7.2) by a glass-Teflon homogenizer with an ice-cold jacket. After centrifugation $(100,000 \mathrm{~g})$ of tissue homogenates at $4{ }^{\circ} \mathrm{C}$ for $1 \mathrm{~h}$, the supernatant was used for determination of methionine synthase (MS) activity, an enzyme that catalyzes the final step in the regeneration of methionine from homocysteine, and intracellular antioxidant enzymes, GSH and TAC concentrations. 
Measurements of antioxidant enzyme, GSH and TAC assays

The following parameters were measured in kidney tissue homogenates according to the manufacturer's instructions: glutathione (GSH) concentration was estimated with a glutathione assay kit (Biovision, K251, Mountain View, CA, USA), and total antioxidant capacity (TAC) was measured using a Randox assay kit (Randox Laboratories Crumlin, UK). All antioxidant enzyme assay kits were purchased from Sigma Chemical Co; for GST (Catalog Number CS0410), for GPx (Catalog Number CGP1), for GR (Catalog Number GRSA), for SOD (Catalog Number 19160), and for CAT (Catalog Number CAT 100).

\section{Methionine synthase (MS) assay}

MS activity in the tissue homogenates was determined by measuring incorporation of radiolabel from [methyl- ${ }^{14} \mathrm{C}$ ] methylfolate into methionine, as previously described (Waly et al. 2004). The reaction mixture contained: $100 \mathrm{mmol} / \mathrm{l}$ potassium phosphate buffer ( $\mathrm{pH}$ 7.2), $500 \mu \mathrm{M} \mathrm{HCY}, 152 \mu \mathrm{M}$ SAM, $2 \mathrm{mM}$ titanium citrate, $0.1 \mu \mathrm{Ci}$ [methyl- ${ }^{14} \mathrm{C}$ ] $\mathrm{MeH} 4 \mathrm{~F}, 10 \mu \mathrm{M}$ cobalamin and $380 \mu \mathrm{l}$ of kidney tissue supernatant in a total volume of $500 \mu \mathrm{l}$. Enzyme assays were performed under anaerobic conditions by bubbling nitrogen gas through stoppered vials for 1 hour at $37^{\circ} \mathrm{C}$ and terminated by heating at $98^{\circ} \mathrm{C}$ for $2 \mathrm{~min}$, after which samples were cooled on ice. Radiolabeled methionine was separated from unreacted radiolabeled methylfolate by passing the reaction mixture through an anion exchange column of DOWEX 1X8 (chloride form). The column was washed with $2 \mathrm{ml}$ of water and the aqueous samples were collected in scintillation vials, to which $7 \mathrm{ml}$ of scintillation fluid was added and the radioactivity was counted. All reported values are normalized to protein content and corrected for the counts observed in control assays in which sample enzyme was omitted.

\section{Assay of creatinine and urea}

Plasma creatinine and urea, and urinary creatinine concentrations were measured spectrophotometrically using commercial kits purchased from Human $\mathrm{GmbH}$ (Wiesbaden, Germany).

\section{Measurement of cytokines}

Plasma IL 10 and IL 6 were measured by an ELISA technique using the kit from R\&D systems (Minneapolis, MN, USA). Plasma C-reactive protein
(CRP) was measured by an ELISA technique using the kit from GenWay Biotec, Inc., USA. Erythropoietin (Epo) concentration was measured in the kidney homogenate by an ELISA technique using the kit from Uscan Life Science Inc., USA.

\section{Blood pressure and heart rate measurements}

Two weeks before the experiment, the rats were handled and accustomed to the procedure of blood pressure recording, using the IITC Life Science tail cuff plethysmography blood pressure system (IITC Life Science Inc., 23924 Victory Blvd, Woodland Hills, CA 91367, USA) as used before in our laboratory (Ali et al. 2011b). Briefly, conscious rats were placed in a restrainer on the champer for warming and allowed to rest inside the cage for $15 \mathrm{~min}$ before blood pressure measurements were taken. Rat tails were placed inside a tail cuff, which was inflated and released three times to allow the animal to be conditioned for the process. Blood pressure was determined at the beginning and end of the treatment.

\section{Renal histopathology}

The kidneys were fixed in $10 \%$ neutral formalin, dehydrated in increasing concentrations of ethanol, cleared with xylene and embedded in paraffin. Five $\mu \mathrm{m}$ sections were prepared from kidney paraffin blocks and stained with hematoxylin and eosin and Masson's trichrome stains, and the microscopic scoring of the kidney sections was carried out in a blind fashion by a pathologist who was unaware of the treatment groups and who assigned a score, as described before (Ali et al. 2010).

\section{Drugs and chemicals}

Adenine was obtained from Sigma (St Louis, MO, USA). Three different brands of Acacia gum were used, BDH AG, purchased from Gentaur (VWR-UK), Supergum $^{\mathrm{TM}}$, EM10, a gift from San-Ei Gen FFI, Inc., Japan, and Sudanese Gum, gifted by Dr Isam Al Sidig (from Gum Nature, Khartoum, Sudan). Aqueous solutions of all the gum samples were prepared freshly every day.

\section{Statistical analysis}

All values are presented as means \pm SEM. The data were analyzed by one-way analysis of variance (ANOVA), followed by the Tukey-Kramer multiple comparison test. A value of $\mathrm{p}<0.05$ was selected as the criterion for statistical significance. All statistical analyses were performed with GraphPad Prism version 4.03 (GraphPad Software Inc, San Diego, CA, USA). 

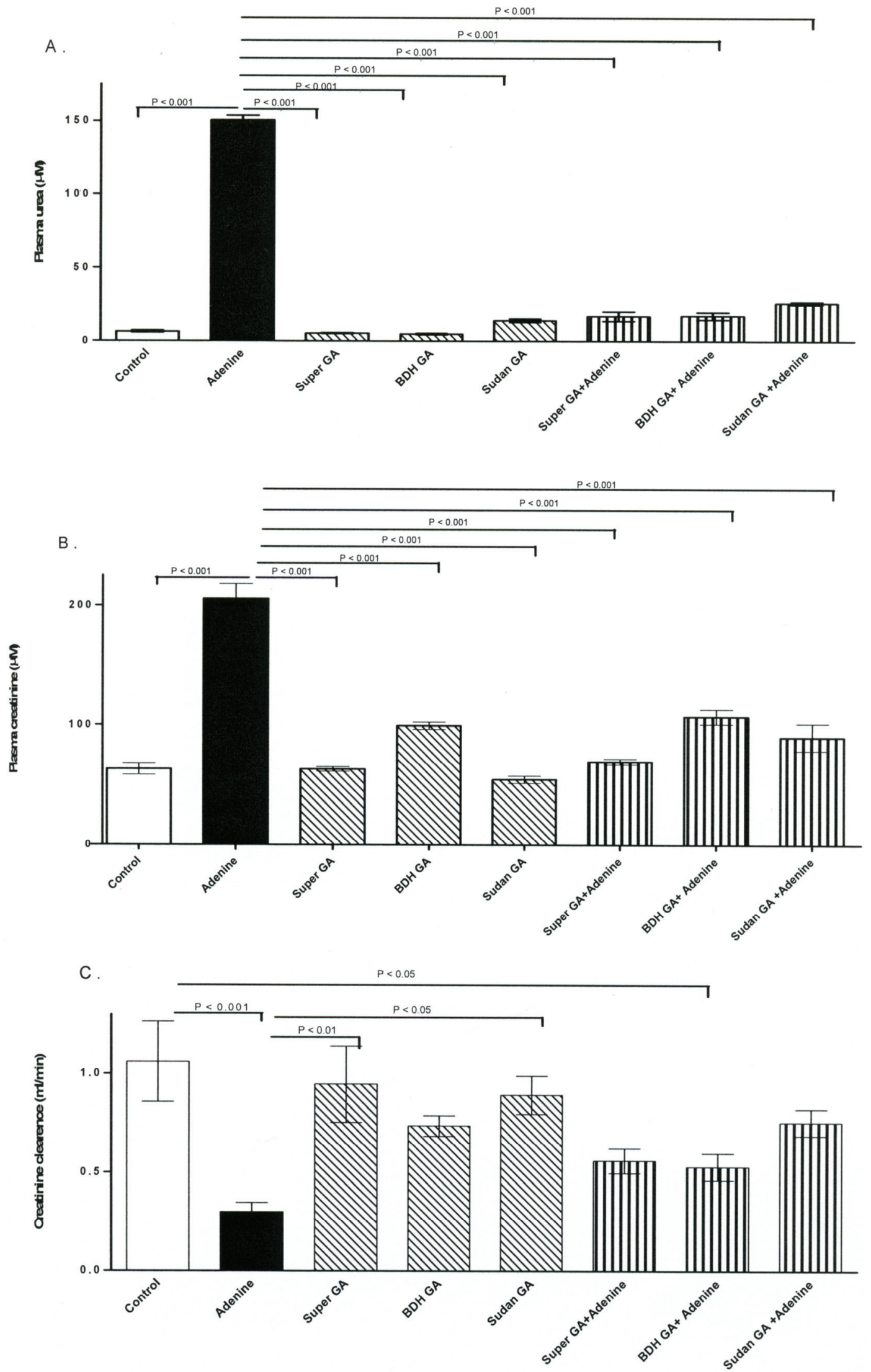

Fig. 1. Urea (A) and creatinine (B) plasma concentrations, and creatinine clearance $(\mathbf{C})$ in control rats, and rats treated with adenine $\left(0.75 \%, w / w\right.$, in the feed), three types of gum acacia (GA), viz Supergum ${ }^{\mathrm{TM}}, \mathrm{BDH}$ GA, and Sudan GA, and also treated with both adenine and the three types of GA, given concomitantly for 28 days at a concentration of $15 \%, w / w$, in the drinking water. Each column and vertical bar represents mean $\pm \operatorname{SEM}(n=6)$. Difference between the groups were assessed by analysis of variance, followed by multiple comparison tests. $p<0.05$ was considered significant. 
Table 1. Effect of three brands of gum acacia on body weight and relative kidney weight in rats fed with adenine $(0.75 \%$, w/w).

\begin{tabular}{llccc}
\hline \multirow{2}{*}{ Group } & \multicolumn{2}{c}{ Body Weight (g) } & BWT change (\%) & Relative kidney WT (\%) \\
& Week 0 & Week 4 & & \\
\hline Control & $345.8 \pm 8.9$ & $411.3 \pm 14.5$ & $18.8 \pm 1.5$ & $0.71 \pm 0.03$ \\
Adenine & $362.8 \pm 10.0$ & $243.3 \pm 6.6^{\mathrm{a}}$ & $-32.9 \pm 0.6^{\mathrm{a}}$ & $2.51 \pm 0.04^{\mathrm{c}}$ \\
Supergum & & & \\
BDH & $399.8 \pm 4.3$ & $429.2 \pm 4.3$ & $7.4 \pm 1.0$ & $0.58 \pm 0.01$ \\
Sudan GA & $379.3 \pm 13.9$ & $397.2 \pm 14.0$ & $4.8 \pm 2.1$ & $0.59 \pm 0.02$ \\
Supergum $^{T M}+$ Adenine & $406.2 \pm 23.2$ & $421.2 \pm 18.6$ & $4.4 \pm 3.9$ & $0.60 \pm 0.05$ \\
BDH GA + Adenine & $395.0 \pm 4.5$ & $276.0 \pm 3.4$ & $-30.1 \pm 0.7^{\mathrm{a}}$ & $1.33 \pm 0.06^{\mathrm{cd}}$ \\
Sudan GA + Adenine & $442.0 \pm 18.3$ & $293.0 \pm 10.5^{\mathrm{b}}$ & $-33.7 \pm 0.9^{\mathrm{a}}$ & $1.49 \pm 0.05^{\mathrm{c}, \mathrm{d}}$ \\
\hline
\end{tabular}

Data are mean $\pm \operatorname{SEM}(n=6)$. Adenine $(0.75 \%, w / w)$ was given daily in the feed for 4 weeks. Three types of GA were given for 4 weeks at a concentration of $(15 \%, w / v)$ in the drinking water. ${ }^{a}$ significantly lower than Control $(\mathrm{P}<0.001) ;{ }^{\mathrm{b}}$ significantly higher than adenine-treated group $(P<0.001) ;{ }^{c}$ significantly higher than Control $(P<0.001) ;{ }^{d}$ significantly lower than adenine-treated group $(\mathrm{P}<0.001)$.

Table 2. Effect of three different types of Gum acacia (GA) on plasma interleukins (IL6), C-reactive protein (CRP) and erythropoietin (Eop) concentrations in plasma and kidneys.

\begin{tabular}{lrccc}
\hline Group & IL6 & CRP & Eop (Plasma) & Eop (Kidney) \\
\hline Control & $78.3 \pm 32.1$ & $69.8 \pm 11.7$ & $7.1 \pm 1.4$ & $19.3 \pm 1.7^{\mathrm{a}}$ \\
Adenine & $72.8 \pm 59.8$ & $76.1 \pm 9.8$ & $12.5 \pm 2.3$ & $11.9 \pm 0.4$ \\
Supergum $^{T M}$ & $108.9 \pm 44.6$ & $45.0 \pm 9.8$ & $6.7 \pm 1.4$ & $19.0 \pm 3.0^{\mathrm{a}}$ \\
BDH GA & $96.7 \pm 39.6$ & $28.1 \pm 9.2^{\mathrm{a}}$ & $5.5 \pm 0.9$ & $18.8 \pm 1.5^{\mathrm{a}}$ \\
Sudan GA & $135.0 \pm 55.3$ & $44.3 \pm 6.3$ & $3.8 \pm 0.6$ & $20.7 \pm 2.2^{\mathrm{d}}$ \\
Supergum $^{T M}+$ Adenine & $55.6 \pm 22.7$ & $26.7 \pm 7.4^{\mathrm{b}}$ & $18.6 \pm 3.3$ & $13.0 \pm 0.9$ \\
BDH GA + Adenine & $72.2 \pm 30.7$ & $14.0 \pm 7.6^{\mathrm{c}}$ & $8.7 \pm 1.1$ & $12.3 \pm 0.2$ \\
Sudan GA + Adenine & $143.9 \pm 59.0$ & $35.4 \pm 8.8^{\mathrm{a}}$ & $8.8 \pm 2.3$ & $12.4 \pm 0.2$ \\
\hline
\end{tabular}

Data are mean $\pm \operatorname{SEM}(n=6)$. The unit of the measured analytes is $\mathrm{IU} / \mathrm{ml}$. Adenine $(0.75 \%$, w/w) was given daily in the feed for 4 weeks. Three types of GA were given for 4 weeks at a concentration of $(15 \%, w / v)$ in the drinking water. ${ }^{a}$ Significantly different

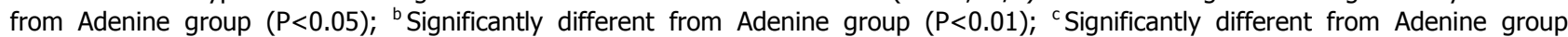
$(P<0.001) ;{ }^{d}$ Significantly different from Adenine group $(P<0.0001)$.

\section{Results}

\section{General effects}

The body weights of the eight groups were significantly changed (Table 1). The body weight of adenine-fed rats was significantly decreased by about $33 \%$ at the end of the treatment. The weights of rats treated with each of the three gums at a concentration of $15 \%, w / w$ in water, were significantly higher than the weights of rats treated with adenine alone $(p<0.05)$. Generally, the condition of adenine-treated rats, and the gross macroscopic appearance of their kidneys were improved to a similar extent by treatment with each of the three types of GA used. The increased weight of the kidneys in adenine-treated rats was more or less equally reversed by the three types of GA. The adenine-fed group consumed more water, and voided more urine compared with the control, an effect that was significantly, but not completely, reversed by treatment with the three types of GA.

\section{Biochemical measurements}

As shown in Fig. 1, adenine feeding significantly increased the concentrations of urea and creatinine in plasma, and significantly decreased creatinine clearance $(p<0.001)$. Treatment with the three types of GA significantly reduced this effect of adenine to a broadly similar extent. The effects of adenine and GA treatments 
Table 3. The effects of different types of Gum acacia (GA) against adenine-induced inhibition of glutathione, total antioxidant capacity (TAC) and antioxidant enzymes in rat kidney tissue homogenates.

\begin{tabular}{lccccccc}
\hline Group & GSH & TAC & GST & GPx & GR & SOD & CAT \\
\hline $\begin{array}{l}\text { Control } \\
\text { Adenine }\end{array}$ & $27.6 \pm 1.8$ & $118.2 \pm 6.4$ & $18.7 \pm 3.1$ & $7.8 \pm 0.9$ & $11.1 \pm 1.7$ & $66.6 \pm 4.1$ & $90.7 \pm 6.3$ \\
$\begin{array}{l}\text { Supergum } \\
+ \text { Adenine }\end{array}$ & $27.7 \pm 3.4^{\mathrm{a}}$ & $68.3 \pm 3.9^{\mathrm{a}}$ & $5.8 \pm 1.2^{\mathrm{a}}$ & $3.2 \pm 0.8^{\mathrm{a}}$ & $5.1 \pm 0.6^{\mathrm{a}}$ & $33.2 \pm 2.3^{\mathrm{a}}$ & $28.4 \pm 4.8^{\mathrm{a}}$ \\
$\begin{array}{l}\text { BDH GA } \\
+ \text { Adenine }\end{array}$ & $117.7 \pm 3.7$ & $18.1 \pm 1.7^{\mathrm{b}}$ & $7.3 \pm 0.6^{\mathrm{b}}$ & $11.4 \pm 1.1^{\mathrm{b}}$ & $65.4 \pm 5.1^{\mathrm{b}}$ & $89.5 \pm 5.8^{\mathrm{b}}$ \\
$\begin{array}{l}\text { Sudan GA } \\
+ \text { Adenine }\end{array}$ & $27.1 \pm 1.9^{\mathrm{c}}$ & $118.1 \pm 4.6^{\mathrm{c}}$ & $18.4 \pm 1.3^{\mathrm{b}}$ & $8.0 \pm 1.4^{\mathrm{b}}$ & $10.9 \pm 1.4^{\mathrm{b}}$ & $65.8 \pm 4.9^{\mathrm{b}}$ & $90.2 \pm 6.3^{\mathrm{b}}$ \\
\hline
\end{tabular}

Data are mean $\pm \operatorname{SEM}(n=6)$. Enzymes activities are expressed as $\mu \mathrm{mol} / \mathrm{min} / \mathrm{mg}$ protein. Adenine $(0.75 \%, \mathrm{w} / \mathrm{w})$ was given daily in the feed for 4 weeks. Three types of GA were given for 4 weeks at a concentration of $(15 \%, w / v)$ in the drinking water. Glutathione and total antioxidant capacity (TAC) are expressed as nmol/mg protein. ${ }^{a}$ significantly lower than Control $(\mathrm{P}<0.05) ;{ }^{\mathrm{b}}$ significantly higher than adenine-treated group $(P<0.05)$, based on one way ANOVA and Tukey's multiple comparison test; ${ }^{c}$ significantly higher than adenine-treated group $(P<0.05)$, based on unpaired Student $t$-test

on the concentration of some inflammatory and antiinflammatory cytokines are shown in Table 2. Adenine significantly decreased renal erythropoietin concentration, and this effect was significantly, and almost completely and equally reversed by the three types of GA used. Treatment with the three GAs alone (particularly the Sudanese variety) markedly, but insignificantly altered the activity of antioxidant enzymes such as GST, GPx, GR, SOD, and CAT in rat renal tissue as shown in the Table 3. Adenine feeding significantly decreased the activity of all the antioxidant enzymes. However, GA fed with adenine $(0.75 \%$, w/w, for 4 weeks) significantly $(\mathrm{p}<0.05)$ ameliorated the effect of the adenine- induced inhibition of antioxidant enzymes in rat kidney tissue homogenates. As shown in Table 3, the total antioxidant capacity and reduced glutathione in adenine-fed rats given GA were significantly $(p<0.05)$ higher than in the adenine-fed group. The activity of MS in the kidney homogenates showed that all rats given GA with adenine had significantly $(\mathrm{p}<0.01)$ higher activity than those that were given adenine alone.

\section{Effect on blood pressure and heart rate}

Adenine feeding $(0.75 \%$, w/w, for 4 weeks $)$ significantly increased the systolic and diastolic blood pressure $(p<0.001)$ at the end of the treatment period. Treatment with the three different gums alone did not significantly alter the blood pressure of treated rats. However, treatment of rats with these gums concomitantly with adenine significantly restored, to a similar extent, the values of systolic and diastolic blood pressure. There were no significant changes in the heart rates in all the treated groups (Fig. 2).

\section{Renal histopathology}

Rats in the control and the three GA groups showed normal kidney architecture and histology, and complete absence of interstitial fibrosis. The adeninetreated groups showed diffuse tubular injury with neutrophil polymorph infiltration, tubular necrosis, tubular atrophy and diffuse interstitial fibrosis (data not shown). Renal histological sections of the rats treated with adenine plus any of the three types of GA used showed marked and similar improvement in comparison with the adenine-treated group. A semiquantitative analysis of renal histology of rats in the different groups showed that the score of histological damage in the control group, as well as groups of rats treated with the three brands of GA was zero. The score of histological damage in the adenine-treated groups was 4 , whereas that in rats treated with adenine and the three different brands of GA was similar (score of 2).

\section{Discussion}

GA is a well known dietary fiber with several uses in the pharmaceutical, cosmetic and food industries (Ali et al. 2009). Recently, this natural product has found use in some hospitals in some Middle Eastern countries (such as Iraq and Sudan) (Ali et al. 2009, Al Mosawi 2009) in patients with CKD. These preliminary reports corroborate a folk medicinal practice in these countries to 

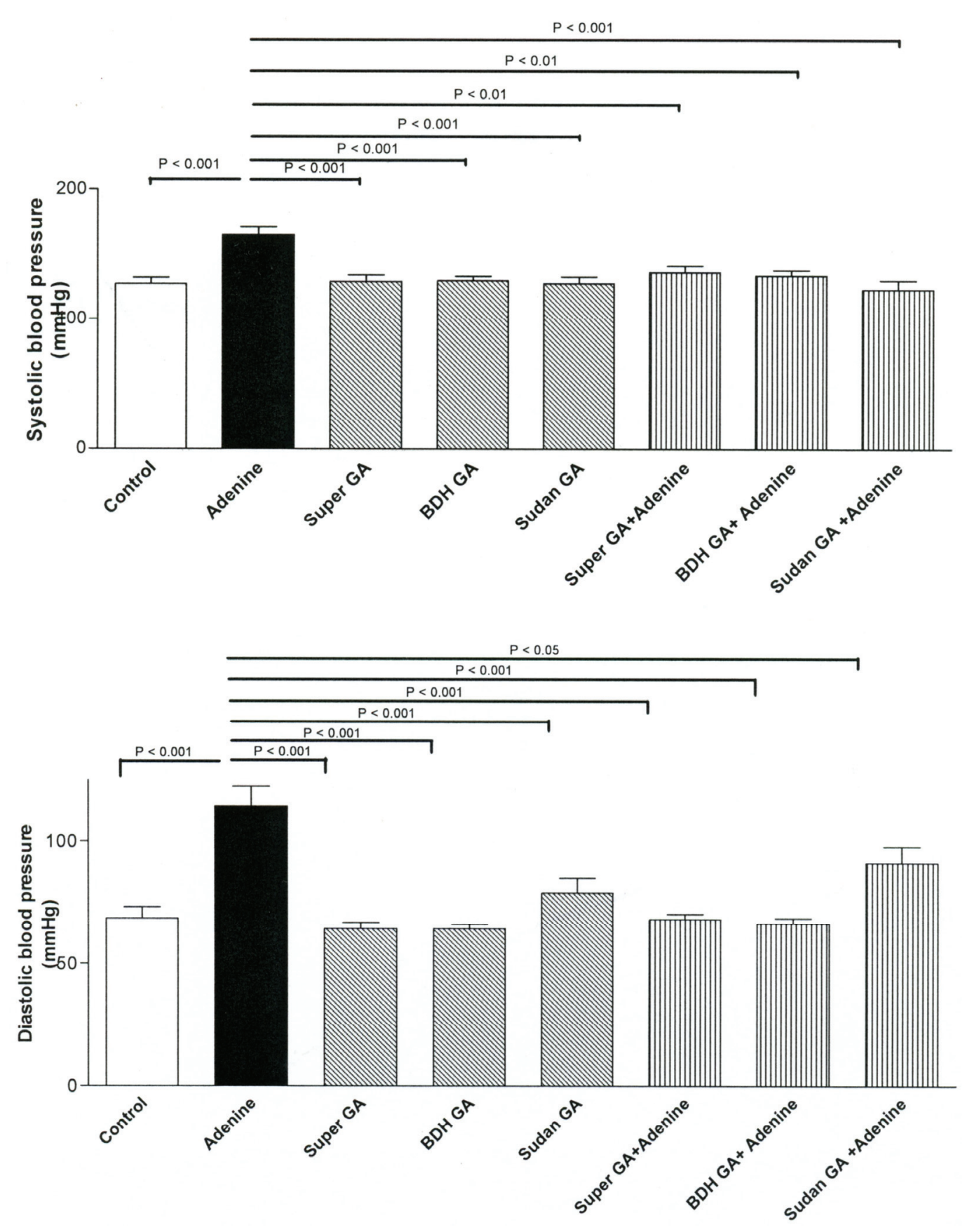

Fig. 2. The systolic and diastolic blood pressure in control rats, and rats treated with adenine $(0.75 \%, w / w$, in the feed), three types of gum acacia (GA), viz Supergum ${ }^{\mathrm{TM}}, \mathrm{BDH}$ GA, and Sudan GA, and also treated with both adenine and the three types of GA, given concomitantly for 28 days at a concentration of $15 \%, w / w$, in the drinking water. Each column and vertical bar represents mean \pm SEM $(n=6)$. Differences between the groups were assessed by analysis of variance, followed by multiple comparison tests. $p<0.05$ was considered significant.

abate some of the effects of renal disease. However, more scientific research is needed, and certainly larger controlled clinical trials are required before this agent is accepted as an adjunct drug in the treatment of CKD. Another important aspect to consider here is the possibility that, like most natural products, different varieties of the same product may yield different results, depending on several factors that may include the species, maturation process, the concentration of the different ingredients present, the season of collection and soil type. For example, it has been shown that exudate gums from A. seyal and A. nilotica have the same sugar and amino acid content, but different arabinogalactan and arabinogalactan-protein epitopes (Mahendran et al. 2008, Menzies et al. 1996). In addition, GAs from different species have been shown to differ from each other in 


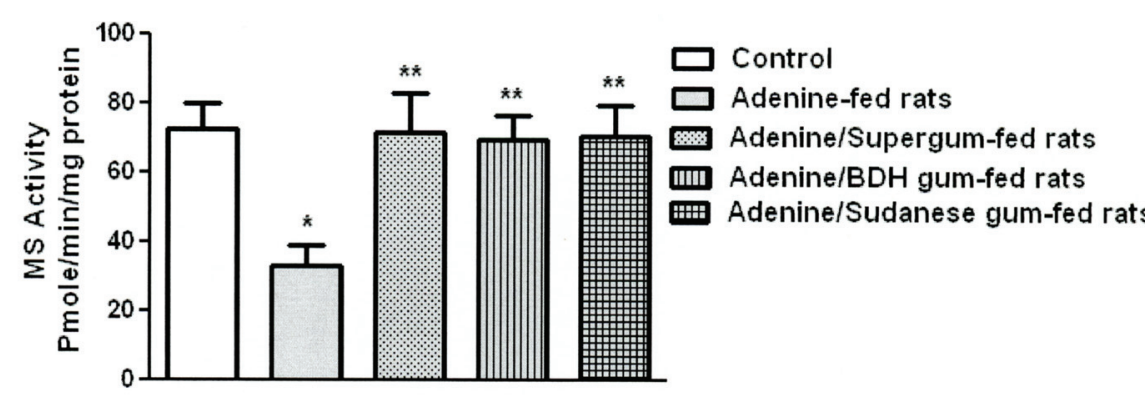

Fig. 3. Methionine synthase (MS) activity of kidney tissue homogenates in control rats, and rats treated with adenine $(0.75 \%, w / w$, in the feed), and three types of gum acacia (GA), viz Supergum $^{T M}, B D H$ GA, and Sudan GA, given concomitantly with both adenine for 28 days at a concentration of $15 \%$, $\mathrm{w} / \mathrm{w}$, in the drinking water. Each column and vertical bar represents mean \pm SEM $(n=6) * p<0.05$, significant decrease when compared to control, ** $p<0.01$, significant increase when compared to adenine-fed rats. several immunological properties (Pickles et al. 2007). As GA is used clinically, albeit on a small scale in some nephrology clinics in some developing countries, and is now widely marketed as a prebiotic in many countries, we thought a comparative study of the biological effects of three commercially available brands may yield some information as to which one would produce the most useful results regarding safety and efficacy. We used in this study one type of GA (Supergum ${ }^{\mathrm{TM}}$ ) that has been well-researched and chemically characterized (Cui et al. 2007), and a type that is widely marketed in Sudan for renal patients, and also as a prebiotic, and also a laboratory-grade GA from a chemical company (BDH). In this work all the biological effects observed by the three brands were broadly similar, and no significant difference between the three gums was detected for any of the parameters studied. These variables were all observed using the Sudan GA and recorded before (Ali et al. 2010, Ali et al. 2011a, Ali et al. 2011b). No comparative analytical study of the three brands of GA has been attempted here, but the effects produced by the three on some established biological actions seem to indicate that the chemical components in GA responsible for the measured biological effects were similar, if not identical. However, this does not negate the fact that it is possible to detect differences in other biological effects among these (and other) types of GA. For that reason, the authors recommend the use in future experiments of chemically-well characterized brands in order to facilitate comparisons of results from different laboratories, and if GA is to be employed as a medicinal agent, it should be well characterized chemically and biologically.

The study confirmed our earlier findings that adenine treatment produces significant decrease in body weight (Ali et al. 2010). Treatment with the three brands of GA alone produced modest (4-7 \%) increases in body weight. However, treatment with any of the three types of GA did not significantly reverse the adenine-induced decrease in body weight (Table 1).

In this work several standard indices of oxidant/antioxidant status have been measured. These included conventional parameters such as reduced glutathione (GSH), as well as relatively novel ones such as Epo and methionine synthase (MS). The former has been shown to have a strong cytoprotective and antioxidative actions (Katavetin et al. 2007), and its renal concentration is known to be reduced in CRF (Srai et al. 2010). MS is a specific index of oxidant/antioxidant status that is not routinely used. We have measured the activity of this enzyme in this work because it is an ubiquitous enzyme that mediates homocysteien transsulfuration into de novo synthesis of GSH, and a reduced MS activity is related to a lower rate of GSH biosynthesis, an index of cellular oxidative stress (Waly et al 2004). Our study reported a reduction in the indices of oxidation stress markers (Table 2) as well as reduced MS activity (Fig. 3). This is consistent with previous reports that have indicated that inhibition of MS activity is associated with a reduced cellular GSH concentration, and proposed the hypothesis that the reduced MS activity is involved in the etiology of impaired cellular oxidation status (Kenyon et al. 2002, Fu et al. 2011). The antioxidant properties of GA have been suggested to be involved in the amelioration of the toxicities of several agents, including acetaminophen hepatotoxicity, doxorubicin cardiotoxicity and cisplatin and gentamicin nephrotoxicity (reviewed by Ali et al. 2009).

From the results obtained, the mechanism(s) by which GA ameliorates adenine-induced CRF in rats may include anti-oxidant and anti-inflammatory actions. The possibility that GA binds with adenine in the gut, and therefore prevents its absorption leading to reduction or prevention of the occurrence of the renal toxicity is highly unlikely, as GA has repeatedly been shown to exert systemic effects after oral administration. For example, it has been reported that in healthy mice, 
treatment with GA resulted in moderate but significant increases of creatinine clearance and altered electrolyte excretion, suggesting favorable actions in renal insufficiency (Nasir et al. 2008). GA has also been shown to have a strong immune-modulatory action in mice (Xuan et al. 2010). More recently, it has been reported that GA treatment decreases blood pressure and proteinuria in diabetic mice and may thus prove beneficial in diabetic nephropathy (Nasir et al. 2012) strongly suggesting that GA has significant systemic, and not only local action in the gut.

Because of the lack of a suitable method for measuring adenine in plasma, our research group has developed an HPLC method for adenine measurement in plasma of rats (Al Za'abi et al. 2013), and this will be used in a pharmacokinetic study to measure adenine concentration in plasma in rats treated with GA and saline. This should directly prove (or disprove) the possibility that GA binds with adenine in the intestine and prevents its absorption.
In conclusion, this work has shown that GA mitigates adenine-induced CKD in rats through an antiinflammatory and antioxidant actions, and that the three brands of GA used in this work were broadly effective in ameliorating the renal effects. However, to enable standardization of different brands between laboratories, the use of the chemically well-characterized GA preparation (such as Supergum ${ }^{\mathrm{TM}}$ ) is recommended.

\section{Conflict of Interest}

There is no conflict of interest.

\section{Acknowledgements}

This work was financially supported by a grant from The Research Council of Oman (RC/Med/ Phar/10/01), and the Sultan Qaboos University (SQU). Thanks are due to Dr Isam Al Sidig for a gift of Sudanese GA, and to the Japanese company San-Ei Gen FFI Inc, and Professor Phillips for providing Supergum ${ }^{\mathrm{TM}}$. We thank the staff of the Animal House of SQU for looking after the rats.

\section{References}

AL-ASSAF S, PHILIPS GO, WILLIAMS PA: Studies on acacia exudate gums: Part 1: The molecular weight of Acacia senegal gum exudate. Food Hydrocoll 19: 647-660, 2005.

AL MOSAWI AJ: Six-year dialysis freedom in end-stage renal disease. Clin Exp Nephrol 13: 494-500, 2009.

AL ZA'ABI M, ALI BH, HUSSEIN A, IMRAN A: Fast HPLC analysis of adenine in human plasma by new generation C28 column and different extraction methods. Anal Methods, In press (2013).

ALI AA, ALI KE, FADLALLA AE, KHALID KE: The effects of gum arabic oral treatment on the metabolic profile of chronic renal failure patients under regular haemodialysis in Central Sudan. Nat Prod Res 22: 12-21, 2008.

ALI BH, ZIADA A, BLUNDEN G: Biological effects of gum arabic: a review of some recent research. Food Chem Toxicol 47: 1-8, 2009.

ALI BH, AL-SALAM S, Al HUSSENI I, KAYED RR, AL-MASROORI N, AL-HARTHI T, AL ZAABI M, NEMMAR A: Effects of Gum Arabic in rats with adenine-induced chronic renal failure. Exp Biol Med (Maywood) 235: 373-382, 2010.

ALI BH, ZIADA A, AL HUSSENI I, BEEGAM S, NEMMAR A: Motor and behavioral changes in rats with adenineinduced chronic renal failure: influence of acacia gum treatment. Exp Biol Med (Maywood) 236: 107-112, $2011 \mathrm{a}$.

ALI BH, ZIADA A, HUSSENI IA, BEEGAM S, Al-RUQAISHI B, NEMMAR A: Effect of Acacia gum on blood pressure in rats with adenine-induced chronic renal failure. Phytomedicine 18: 1176-1180, $2011 \mathrm{~b}$.

BLISS DZ, STEIN TP, SCHLEIFER CR, SETTLE RG: Supplementation with gum Arabic fiber increases fecal nitrogen excretion and lowers serum urea nitrogen concentration in chronic renal failure patients consuming a low-protein diet. Am J Clin Nutr 63: 392-398, 1996.

CUI SW, PHILLIPS GO, BLACKWELL B, NIKIFORUK J: Characterisation and properties of Acacia senegal (L.) Willd. var. senegal with enhanced properties (Acacia (sen) SUPERGUMTM): Part 4. Spectroscopic characterisation of Acacia senegal var. senegal and Acacia (sen) SUPERGUM• arabic. Food Hydrocoll 21: 347-352, 2007.

FU T, ALMQVIST J, LIANG Y, LI L, HUANG Y, SU X: Crystal structures of cobalamin-independent methionine synthase from Streptococcus mutans: a dynamic zinc-inversion model. J Mol Biol 412: 688-697, 2011. 
KATAVETIN P, TUNGSANGA K, EIAM-ONG S, NANGAKU M: Antioxidative effects of erythropoietin. Kidney Int Suppl 107: S10-S15, 2007.

KENYON SH, WATERFIELD CJ, TIMBRELL JA, NICOLAOU A: Methionine synthase activity and sulphur amino acid levels in the rat liver tumor cells. Biochem Pharmacol 63: 381-391, 2002.

LELON JK, JUMBA IO, KETER JK, CHEMUKU W, ODUOR FDO: Assessment of physical properties of gum arabic from Acacia senegal varieties in Baringo District, Kenya. Afr J Plant Sci 4: 95-98, 2010.

MAHENDRAN T, WILLIAMS PA, PHILLIPS GO, AL-ASSAF S, BALDWIN TC: New insights into the structural characteristics of the arabinogalactan-protein (AGP) fraction of gum arabic. J Agric Food Chem 56: 92699276, 2008.

MENZIES AR, OSMAN ME, MALIK AA, BALDWIN TC: A comparison of the physicochemical and immunological properties of the plant gum exudates of Acacia senegal (gum arabic) and Acacia seyal (gum tahla). Food Addit Contam 13: 991-999, 1996.

NASIR O, ARTUNC F, SAEED A, KAMBAL MA, KALBACHER H, SANDULACHE D, BOINI KM, JAHOVIC N, LANG F: Effects of gum arabic on water and electrolyte balance in healthy mice. $J$ Ren Nutr 18: 230-238, 2008.

NASIR O, UMBACH AT, REXHEPAJ R, ACKERMANN TF, BHANDARU M, EBRAHIM A, ARTUNC F, KEMPE DS, PUCHCHAKAYALA G, SIRASKAR B, FÖLLER M, SAEED A, LANG F: Effects of gum arabic (Acacia senegal) on renal function in diabetic mice. Kidney Blood Press Res 35: 365-372, 2012.

PICKLES NA, AOKI H, AL-ASSAF S, SAKATA M, OGASAWARA T, IRELAND HE, COLEMAN RC, PHILLIPS GO, WILLIAMS JHH: Characterisation and properties of Acacia senegal (L.) Willd. var. senegal with enhanced properties (Acacia (sen) SUPER GUM ${ }^{\mathrm{TM}}$ ): Part 3 Immunological characterisation of Acacia (sen) SUPER GUM ${ }^{\mathrm{TM}}$. Food Hydrocoll 21: 338-346, 2007.

SRAI SK, CHUNG B, MARKS J, POURVALI K, SOLANKY N, RAPISARDA C, CHASTON TB, HANIF R, UNWIN RJ, DEBNAM ES, SHARP PA: Erythropoietin regulates intestinal iron absorption in a rat model of chronic renal failure. Kidney Int 78: 660-667, 2010.

XUAN NT, SHUMILINA E, NASIR O, BOBBALA D, GÖTZ F, LANG F: Stimulation of mouse dendritic cells by Gum Arabic. Cell Physiol Biochem 25: 641-648, 2010.

WALY M, OLTEANU H, BANERJEE R, CHOI SW, MASON JB, PARKER BS, SUKUMAR S, SHIM S, SHARMA A, BENZERCY JM, POWER-CHARNITSKY VA, DETH RC: Activation of methionine synthase by insulinlike growth factor-1 and dopamine: a target for neurodevelopmental toxins and thimerosal. Mol Psychiatry 9: 358-370, 2004.

WILLIAMS PA, PHILLIPS GO: Gum arabic. In: Handbook of Hydrocolloids. GO PHILLIPS, PA WILLIAMS (eds), CRC Press, Boca Raton, FL, 2000, pp 155-168. 